\title{
Decolourization of chicken compost derived liquid fertilizer via synergic ultraviolet (UV) irradiation and ozonation for enhanced microalgae cultivation
}

\author{
Yik Lam Kam ${ }^{1,2,3}$, Man Kee Lam ${ }^{1,2, *}$, Yoke Wang Cheng ${ }^{1,2}$, Yaleeni Kanna Dasan ${ }^{1,2}$, Sie Yon Lau ${ }^{4}$, Inn Shi Tan ${ }^{4}$, Henry \\ Chee Yew Foo ${ }^{4}$ \\ ${ }^{1}$ Chemical Engineering Department, Universiti Teknologi PETRONAS, Seri Iskandar 32610, Perak, Malaysia. \\ ${ }^{2} \mathrm{HICoE}-\mathrm{Centre}$ for Biofuel and Biochemical Research, Universiti Teknologi PETRONAS, Seri Iskandar 32610, Perak, Malaysia. \\ ${ }^{3}$ Graduate School of Science and Technology, Kumamoto University, Japan. \\ ${ }^{4}$ Department of Chemical Engineering, Faculty of Engineering and Science, Curtin University, 98009, Sarawak, Malaysia.
}

\begin{abstract}
Compost-derived liquid fertilizers are uncostly and nutrient-enriched; however, its dark brown appearance limits light uptake of microalgae during autotrophic cultivation. Here, integrated UV irradiation/ozonation pretreatment was employed to decolourize the compost solution prior to microalgae cultivation. Aforesaid pretreatment could accomplish $16.52 \%(8 \mathrm{~h})$ or $40.88 \%(24 \mathrm{~h})$ decolorization efficiency by using optimal parameters (initial $\mathrm{pH}$ of 12 , ozone concentration of $30 \mathrm{mg} / \mathrm{L}$, and ozone flow rate of $3 \mathrm{~L} / \mathrm{min}$. Compared to untreated compost solution, microalgae Chlorella vulgaris grew better in the medium supplemented with decolourized compost solution (after $24 \mathrm{~h}$ UV irradiation/ozonation). For the autotrophic cultivation of $C$. vulgaris with 10 vol.\% compost solution, UV irradiation/ozonation pretreatment eventually increases the microalgae dry weight, specific growth rate, and biomass productivity from $0.58 \mathrm{~g} / \mathrm{L}, 0.14 \mathrm{~d}^{-1}$, and $0.040 \mathrm{~g} /(\mathrm{L} \cdot \mathrm{d})$ to $0.88 \mathrm{~g} / \mathrm{L}, 0.19 \mathrm{~d}^{-1}$, and $0.065 \mathrm{~g} /(\mathrm{L} \cdot \mathrm{d})$, respectively. Furthermore, the lipid content of microalgae has been increased by $33.33 \%$ with pretreatment of compost solution.
\end{abstract}

\section{Introduction}

In recent years, microalgae have been touted as a potential biodiesel feedstock $[1,2]$. Unlike multicellular terrestrial oil crops, the unicellular microalgae perform photosynthesis more efficiently, so its rapid reproduction renders its higher biomass production rate $[1,3]$. Besides, microalgae cultivation does not require a large area of high-quality arable land, thereby eventually reduces its production cost $[1,4]$. In brief, production of microalgal biodiesel consists of four basic steps, viz. microalgae cultivation, microalgae harvesting, lipid extraction, and transesterification of microalgal lipid.

During microalgae cultivation, supplementation of the inorganic fertilizers are often required to provide essential nutrients like nitrogen and phosphorus, which crucial for microalgae growth [4]. Inorganic fertilizers are costly till account for up to circa $80 \%$ of total production cost [4], so its usage discourages massive microalgae production. In addition, leaching of nitrogen and phosphorus content from conventional fertilizer into waterway could provoke environmental issue like eutrophication [5]. Alternatively, the integration of wastewater treatment with microalgae cultivation is attractive since pollutant-laden wastewater is remediated via nutrient uptake of microalgae [6]. Apart from high availability, the utilization of industrial effluent as a cultivation medium can reduce consumption of clean water. However, application of wastewater in microalgae cultivation is associated with several drawbacks, such as (i) complex pretreatments are necessary, (ii) concentrated heavy metal ions are detrimental to microalgae, and (iii) high turbidity restricts light penetration ability $[7,8]$.

In contrast, organic fertilizers such as composts from the composting of food or animal waste are cheap nutrient source to cultivate microalgae. Low price of composts is attributed to simple composting process of unwanted raw materials. Like wastewater, the composts are well-known for their high concentration of nitrogen and phosphorus, which essential to microalgae growth $[4,9]$. For nutrient application, the composts are preferred over wastewater as it is free from heavy metal ions, which possibly retard the microalgae growth [3, 8]. Previous studies show that the microalgae Chlorella sp. grew well in the cultivation medium with added compost solution [1].

Direct application of compost derived liquid fertilizer in microalgae cultivation is technically possible, and have been experimentally validated in our previous study [10]. Compost solution appears in dark brown colour, ascribed to humus-like particles that originated from composting process [4]. The addition of dark brown compost solution to the cultivation medium increases its turbidity, which unfavours autotrophic cultivation of microalgae owing to lower accessible light energy [4, 11]. For turbid medium, the microalgae on the interior side experience limited light penetration, which in turns its sluggish growth because of a lower light uptake rate [4]. Hence, the colour issue of compost solution should be tackled in order to improve the microalgae cultivation.

\footnotetext{
Corresponding author: lam.mankee@utp.edu.my
} 
Advanced oxidation processes such as photocatalysis, ultraviolet/hydrogen peroxide $\left(\mathrm{UV} / \mathrm{H}_{2} \mathrm{O}_{2}\right)$, and ozonation could effectively decolourize wastewater through in-situ generation of hydroxyl radicals (HO') [12-14]. UV/ $\mathrm{H}_{2} \mathrm{O}_{2}$ system and photocatalysis require UV irradiation, and the former uses dangerous oxidizer $\left(\mathrm{H}_{2} \mathrm{O}_{2}\right)$ whereas the latter needs pricy catalysts. Despite ozonation generates highly oxidative ozone $\left(\mathrm{O}_{3}\right)$, the ease control of ozone generator makes ozonation less harmful than $\mathrm{UV} / \mathrm{H}_{2} \mathrm{O}_{2}$ system. By decolourizing liquid fertilizer with $\mathrm{UV} / \mathrm{H}_{2} \mathrm{O}_{2}$, the biomass productivity of microalgae increased by 2.1 times [4].

To the best of authors' knowledge, UV irradiation and ozonation have not integratedly applied to decolourize the compost solution for microalgae cultivation. Herein, UV irradiation and ozonation synergistically decolourize the compost solution. Cultivation medium that supplemented with treated compost solution is less opaque than that of untreated one. To conclude, integrated UV irradiation and ozonation as pretreatment of organic fertilizer boosts the photosynthetic growth of microalgae by granting a greater light transmittance.

\section{Material and methods}

\subsection{Cultivation of microalgae seed}

Chlorella vulgaris microalgae seed was retrieved from the laboratory of School of Chemical Engineering, Universiti Sains Malaysia. The microalgae were cultivated in Bold's Basal Medium (BBM) [3]. The initial $\mathrm{pH}$ of medium was altered to 6.8 with $1 \mathrm{M} \mathrm{NaOH}$ or $1 \mathrm{M} \mathrm{H}_{2} \mathrm{SO}_{4}$. The working volume and cultivation temperature of medium were kept at $500 \mathrm{~mL}$ and $25-28{ }^{\circ} \mathrm{C}$, respectively. The medium was aerated with compressed air and illuminated with coolwhite fluorescent light (Philip TL-D 36 W/965, light intensity $\left.=60-70 \mu \mathrm{mol} /\left(\mathrm{m}^{2} \cdot \mathrm{s}\right)\right)[10]$.

\subsection{Preparation of compost solution}

Compost solution with a solvent-to-solute ratio of 60 was prepared by dissolving locally available chicken compost $(10 \mathrm{~g})$ in tap water $(600 \mathrm{~mL})$. After $24 \mathrm{~h}$ of stirring, nonsoluble particulate was filtered from compost solution via vacuum filtration with Double Rings filter paper (average pore size of $20-25 \mu \mathrm{m}$ ). The filtered compost solution was a dark brown liquor, which later refrigerated at $4{ }^{\circ} \mathrm{C}$ for preservation [10].

\subsection{Decolourization of compost solution}

Before decolourization, the compost solution was diluted with tap water to 4 vol.\% compost solution. Three possible pretreatment methods were attempted to decolourize $1.8 \mathrm{~L}$ of compost solution, viz. UV irradiation, ozonation, and UV irradiation/ozonation. The pretreatment duration was investigated from $2-8 \mathrm{~h}$. The initial $\mathrm{pH}$ of compost solution was adjusted to 12 by adding $1 \mathrm{M} \mathrm{NaOH}$ or $1 \mathrm{M} \mathrm{H}_{2} \mathrm{SO}_{4}$. General purpose mercury-vapor UV lamp (5-W power) and ozone generator (A2Z MP-8000) were used to generate UV light

\footnotetext{
* Corresponding author: lam.mankee@utp.edu.my
}

and ozone. For method screening stage, ozone flow rate of $3 \mathrm{~L} / \mathrm{min}$ and ozone concentration of $30 \mathrm{mg} / \mathrm{L}$ were applied whenever ozonation was involved.

In this study, UV irradiation/ozonation represents the most effective approach to decolourize compost solution. Henceforth, this pretreatment was scrutinized to reveal the influence of initial $\mathrm{pH}(2,7,12)$, ozone concentration $(10-30 \mathrm{mg} / \mathrm{L})$, and ozone flow rate $(1-3 \mathrm{~L} / \mathrm{min})$ on the decolourization efficiency. After identification of optimal parameters, the UV irradiation/ozonation pretreatment of compost solution was prolonged from $8-24 \mathrm{~h}$ for better decolourization before microalgae cultivation.

\subsection{Microalgae cultivation with compost solution}

For 14 days, $C$. vulgaris was grown autotrophically in $1 \mathrm{~L}$ photobioreactor at $25 \pm 5{ }^{\circ} \mathrm{C}$. The cultivation medium composed of seed culture, compost solution (treated or untreated), and tap water with a volumetric ratio of $1: 1: 8$. The initial $\mathrm{pH}$ of medium was altered to 3 with $1 \mathrm{M} \mathrm{NaOH}$ or $1 \mathrm{M} \mathrm{H}_{2} \mathrm{SO}_{4}$ [10]. The medium was simultaneously airaerated $(0.4 \mathrm{~L} / \mathrm{min})$ and light-illuminated. Subsequently, the concentration of treated compost solution in medium was varied from $2-10$ vol.\% by adjusting the volume of tap water.

\subsection{Microalgae harvesting}

Suspended microalgae were collected by sedimentation of medium after 2 days. Water on top layer was discarded to get a concentrated microalgae solution, which was ovendried at $110^{\circ} \mathrm{C}$ for $24 \mathrm{~h}$. Then, dry weight of microalgae biomass was measured.

\subsection{Analytical procedures}

For method screening, total nitrate $\left(\mathrm{NO}_{3}{ }^{-}\right)$analysis was performed on 4 vol.\% compost solutions (untreated and treated with UV irradiation/ozonation) using a portable Vernier nitrate ion-selective electrode.

From previous study, dark-brown liquid fertilizer has a maximum absorbance at specified wavelength $(\lambda)$ of $290 \mathrm{~nm}$ [4]. Suitability of absorbance at $\lambda=290 \mathrm{~nm}\left(A_{290}\right)$ to indicate the colour intensity of compost solution was verified by ultraviolet-visible light (UV-Vis) spectroscopy. A UV-Vis spectrophotometer (Shimadzu UV-1280) was used to conduct survey scan of untreated compost solution for $\lambda$ range of $200-800 \mathrm{~nm}$. Hence, decolourization efficiency was expressed as Eq. (1).

$$
X_{A}=\left(\frac{A_{290, i}-A_{290, f}}{A_{290, i}}\right) \times 100 \%
$$

where $X_{A}$ is the decolourization efficiency (\%), $A_{290, i}$ and $A_{290, f}$ are the initial and final absorbance at $\lambda=290 \mathrm{~nm}$, respectively.

Analogously, the green cultivation medium exhibits a maximum absorbance at $\lambda=688 \mathrm{~nm}\left(\mathrm{~A}_{688}\right)$. A calibration curve between the dry weight of microalgae biomass $(N)$ and the $\mathrm{A}_{688}$ was plotted earlier. Hence, $\mathrm{N}$ was predicted from $A_{688}$ via their linear correlation as in Eq. (2) [10]. 
The specific growth rate $(\mu)$ and biomass productivity (B) were calculated using Eq. (3) and (4), respectively [10].

$$
\mathrm{N}=0.3983 \mathrm{~A}_{688} ; \mathrm{R}^{2}=0.98
$$

where $\mathrm{N}$ is the microalgae dry weight $(\mathrm{g} / \mathrm{L}), \mathrm{A}_{688}$ is the absorbance of cultivation medium at $\lambda=688 \mathrm{~nm}$, and $\mathrm{R}^{2}$ is the coefficient of determination.

$$
\begin{gathered}
\mu=\frac{\ln \left(\mathrm{N}_{2} / \mathrm{N}_{1}\right)}{\mathrm{t}_{2}-\mathrm{t}_{1}} \\
\mathrm{~B}=\frac{\mathrm{N}_{2}-\mathrm{N}_{1}}{\mathrm{t}_{2}-\mathrm{t}_{1}}
\end{gathered}
$$

where $\mu$ is the specific growth rate $\left(\mathrm{d}^{-1}\right), B$ is the biomass productivity $(\mathrm{g} /(\mathrm{L} \cdot$ day $))$, and $t$ is the cultivation day $(\mathrm{d})$.

For lipid extraction, dried microalgae biomass $(0.2 \mathrm{~g})$ was mixed with methanol-chloroform (volumetric ratio of $2: 1)$ solution $(60 \mathrm{~mL})$ for $24 \mathrm{~h}$ [10]. The mixture was filtered with filter paper (average pore size of $20-25 \mu \mathrm{m}$ ), air-purged, and oven-dried at $110^{\circ} \mathrm{C}$ for $24 \mathrm{~h}$. The dry weight of microalgal lipid (L) was measured. The lipid content of microalgae $\left(\mathrm{C}_{\mathrm{L}}\right)$ could be computed via Eq. (5).

$$
\mathrm{C}_{\mathrm{L}}=\frac{\mathrm{L}}{\mathrm{N}} \times 100 \%
$$

where $\mathrm{C}_{\mathrm{L}}$ is the lipid content (wt.\%) and $\mathrm{L}$ is the dry weight of microalgal lipid (g).

\section{Results and Discussion}

\subsection{Screening of pretreatment methods}

For method screening stage, the initial $\mathrm{pH}$, volume, and concentration of compost solution were fixed as $12,1.8 \mathrm{~L}$, and 4 vol.\%, respectively. Fig. 1 shows the dependence of decolorization efficiency on pretreatment method, which was ranked as UV irradiation/ozonation $(16.52 \%)>\mathrm{UV}$ irradiation $(5.16 \%)>$ ozonation $(3.31 \%)$. UV irradiation certainly sterilizes the compost solution [15] and slightly degrades its chromophoric humus particles via photolysis [16]. For ozonation, oxidative degradation of humus particles only relies on the ozone (standard oxidation potential, $\mathrm{E}^{\mathrm{o}}=2.07 \mathrm{~V}$ ) [17]. UV irradiation and ozonation were ineffective to degrade humus particles in compost solution, judging from trivial decolourization efficiencies.

The highest decolourization efficiency was attained by UV irradiation/ozonation, attributed to synergistic effect of individual pretreatments. Under UV irradiation, ozone $\left(\mathrm{O}_{3}\right)$ possibly reacts with water to form myriad oxidants, viz. hydroxyl radicals $\left(\mathrm{HO}^{\circ}, \mathrm{E}^{\circ}=2.80 \mathrm{~V}\right)$, hydroperoxyl radicals $\left(\mathrm{HO}_{2}^{\circ}, \mathrm{E}^{\mathrm{o}}=1.46 \mathrm{~V}\right)$, hydrotrioxyl radicals $\left(\mathrm{HO}_{3}{ }^{\circ}\right.$, $\mathrm{E}^{\mathrm{o}}=$ unknown), ozonide radicals $\left(\mathrm{O}_{3^{\circ}}{ }^{-}, \mathrm{E}^{\mathrm{o}}=1.60 \mathrm{~V}\right)$, superoxide radicals $\left(\mathrm{O}_{2}{ }^{\circ-}, \mathrm{E}^{\mathrm{o}}=0.94 \mathrm{~V}\right)$, and oxygen $\left(\mathrm{O}_{2}\right.$, $\left.\mathrm{E}^{\mathrm{o}}=1.23 \mathrm{~V}\right)[12,18-23]$. As shown in Eq. (6), water occasionally self-ionizes to form hydrogen $\left(\mathrm{H}^{+}\right)$and hydroxyl $\left(\mathrm{HO}^{-}\right)$ions [12]. To date, known $\mathrm{UV} / \mathrm{O}_{3}^{-}$ mediated reaction pathways that responsible for the $\mathrm{HO}^{\circ}$ formation include (i) Eqs. (7) - (10), (ii) Eq. (11), (iii) Eqs. (12) - (13), and (iv) Eqs. (12), (14) - (15) [18, 23]. $\mathrm{UV} / \mathrm{O}_{3}$-mediated reactions not only generate highly * Corresponding author: lam.mankee@utp.edu.my reactive $\mathrm{HO}^{*}$, but also produce few other oxidants from $\mathrm{H}^{+}$ and $\mathrm{HO}^{-}$as intermediate by-products [4]. In-situ generation of $\mathrm{HO}^{\circ}$ and other oxidants enhance degradation of chromophoric humus particles in compost solution. Thus, UV irradiation/ozonation outperformed UV irradiation and ozonation in terms of decolourization.

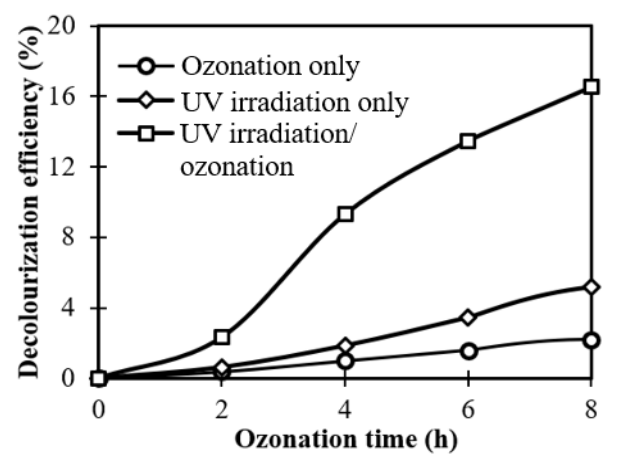

Fig. 1. Decolourization efficiency of different pretreatment methods on compost solution.

$$
\begin{gathered}
\mathrm{H}_{2} \mathrm{O} \leftrightarrow \mathrm{H}^{+}+\mathrm{HO}^{-} \\
\mathrm{O}_{3}+\mathrm{HO}^{-} \stackrel{h v}{\rightarrow} \mathrm{HO}_{2}^{-}+\mathrm{O}_{2} \\
\mathrm{O}_{3}+\mathrm{HO}_{2}^{-} \rightarrow \mathrm{HO}_{2}^{-}+\mathrm{O}_{3}^{--} \\
\mathrm{O}_{3}^{--}+\mathrm{H}^{+} \rightarrow \mathrm{HO}_{3}^{-} \\
\mathrm{HO}_{3}^{-} \rightarrow \mathrm{HO}^{-}+\mathrm{O}_{2} \\
3 \mathrm{O}_{3}+\mathrm{H}_{2} \mathrm{O} \stackrel{h v}{\rightarrow} 2 \mathrm{HO}^{-}+4 \mathrm{O}_{2} \\
\mathrm{O}_{3}+\mathrm{H}_{2} \mathrm{O} \stackrel{h v}{\rightarrow} \mathrm{H}_{2} \mathrm{O}_{2}+\mathrm{O}_{2} \\
\mathrm{H}_{2} \mathrm{O}_{2} \stackrel{h v}{\rightarrow} 2 \mathrm{HO}^{-} \\
\mathrm{H}_{2} \mathrm{O}_{2} \rightarrow \mathrm{HO}_{2}^{-}+\mathrm{H}^{+} \\
\mathrm{O}_{3}+\mathrm{HO}_{2}^{-} \rightarrow \mathrm{HO}^{-}+\mathrm{O}_{2}^{-}+\mathrm{O}_{2}
\end{gathered}
$$

After UV irradiation/ozonation, dark brown compost solution became faded and eventually transformed into a translucent yellowish-brown solution. As disclosed by the total nitrate analysis, no disparity in nitrate concentration was observed between untreated $(35.3 \mathrm{mg} / \mathrm{L})$ and treated (35 mg/L) compost solutions. UV irradiation/ozonation did not reduce the nutrient content of compost solution (specifically $\mathrm{NO}^{3-}$ ) despite its effective decolourization. UV irradiation/ozonation was deemed the most suitable pretreatment to decolourize compost solution. Therefore, only UV irradiation/ozonation was further investigated in subsequent works.

\subsection{Influence of pretreatment parameters on the decolourization of compost solution}

\subsubsection{Effect of initial $\mathrm{pH}$}

The ozone concentration and flow rate were fixed as $30 \mathrm{mg} / \mathrm{L}$ and $3 \mathrm{~L} / \mathrm{min}$ to reveal the effect of initial $\mathrm{pH}$ on decolourization efficiency of UV irradiation/ozonation. Fig. 2 shows that the decolourization efficiency increased with prolonged pretreatment since more humus particles in the compost solution were degraded over time. Under alkaline environment ( $\mathrm{pH}$ 12), UV irradiation/ozonation attained the highest decolourization efficiency (16.52\%), and such effectiveness informed ozone instability at high 
$\mathrm{pH}$. As mentioned in Section 3.1, ozone could react with water via 4 possible reaction pathways $[18,23]$, but ozone preferentially reacts with ionized species (like $\mathrm{H}^{+}$and $\mathrm{HO}^{-}$ ) [23]. Thence, it is surmised Eqs. (7) - (10) represent the primary $\mathrm{UV} / \mathrm{O}_{3}$-mediated reaction pathway. Plentiful $\mathrm{HO}^{-}$ ions in basified compost solution shifted the equilibrium of Eq. (7) to forward direction, which eventually formed more $\mathrm{HO}^{\circ}$ via Eqs. (8) - (10). In relative to $\mathrm{O}_{3}$, the $\mathrm{HO}^{\circ}$ is far more reactive, so the oxidative degradation of humus particles is amplified in alkaline compost solution [17].

On the other hand, UV irradiation/ozonation achieved $12.38 \%$ decolourization efficiency in acidic environment ( $\mathrm{pH} 2)$, which is lower than that of $\mathrm{pH}$ 12. Instead of $\mathrm{HO}^{-}$ , abundant $\mathrm{H}^{+}$ions exist in the acidified compost solution. Without additional $\mathrm{HO}^{-}$, the forward reaction of Eq. (7) is not prevail. Nonetheless, plentiful $\mathrm{H}^{+}$ultimately expedites forward reaction of Eq. (9), viz. an intermediate reaction before $\mathrm{HO}^{\bullet}$ formation via Eq. (10). In short, the formation of $\mathrm{HO}^{\circ}$ in the acidified solution is lagged behind that of basified solution. At low $\mathrm{pH}$, most of the humus particles in compost solution are directly oxidised by $\mathrm{O}_{3}$, which is less destructive than $\mathrm{HO}^{*}$ [17]. The inferior performance of UV irradiation/ozonation at low $\mathrm{pH}$ is likely associated with less favourable $\mathrm{HO}^{\bullet}$ formation.

At neutral $\mathrm{pH}(\mathrm{pH} 7)$, the UV irradiation/ozonation of compost solution was the least effective with only $5.01 \%$ decolourization efficiency. No additional $\mathrm{H}^{+}$and $\mathrm{HO}^{-}$ions are present in neutral compost solution, and hence neither the reactions in Eq. (7) or (9) are promoted. For neutral compost solution, the degradation of humus particles via Eqs. (7) - (10) is plausible but with a slower rate, credited to spontaneous self-ionization of water molecules [12]. Under UV irradiation/ozonation, neutral compost solution is likely decolourized by various interactions between $\mathrm{O}_{3}$ and $\mathrm{H}_{2} \mathrm{O}$, as described in (i) Eq. (11), (ii) Eqs. (12) - (13), and/or (iii) Eqs. (12), (14) - (15). In remaining study, initial $\mathrm{pH}$ of 12 is recommended as it decolourize compost solution most effectively.

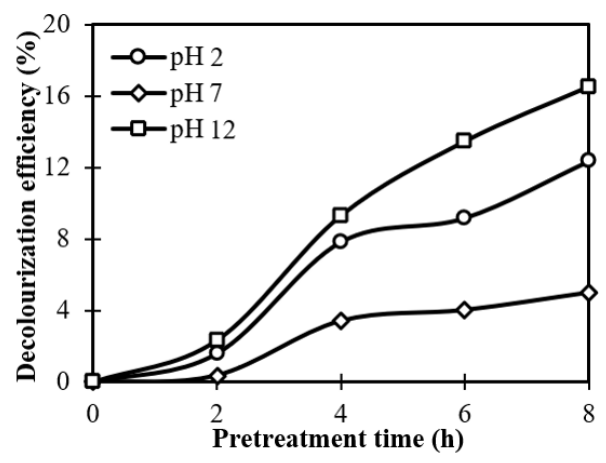

Fig. 2. Effect of initial $\mathrm{pH}$ on decolourization efficiency of UV irradiation/ozonation pretreatment.

\subsubsection{Effect of ozone concentration}

The initial $\mathrm{pH}$ and ozone flow rate were kept constant as 12 and $3 \mathrm{~L} / \mathrm{min}$ to reveal the effect of ozone concentration on decolourization efficiency of UV irradiation/ozonation for compost solution. As depicted in Fig. 3, the increase of ozone concentration from $10-30 \mathrm{mg} / \mathrm{L}$ enhances the decolourization efficiency since more $\mathrm{O}_{3}$ are continuously introduced to the compost solution. Supposedly, a greater $\mathrm{O}_{3}$ concentration renders a higher $\mathrm{HO}^{*}$ formation rate as more $\mathrm{O}_{3}$ species could react with $\mathrm{HO}^{-}$ions (from alkaline environment) via Eq. (7) [18]. High $\mathrm{O}_{3}$ concentration promotes the in-situ generation of highly reactive $\mathrm{HO}^{\circ}$, which leads to higher degradation rate of humus particles. When pretreatment is extended, basified compost solution gradually faded over time. After $8 \mathrm{~h}$, the pretreatment with $\mathrm{O}_{3}$ concentration of $10 \mathrm{mg} / \mathrm{L}, 20 \mathrm{mg} / \mathrm{L}$, and $30 \mathrm{mg} / \mathrm{L}$ attained decolourization efficiency of $12.70 \%, 14.09 \%$, and $16.52 \%$, individually. Hence, $\mathrm{O}_{3}$ concentration of $30 \mathrm{mg} / \mathrm{L}$ is used for subsequent work.

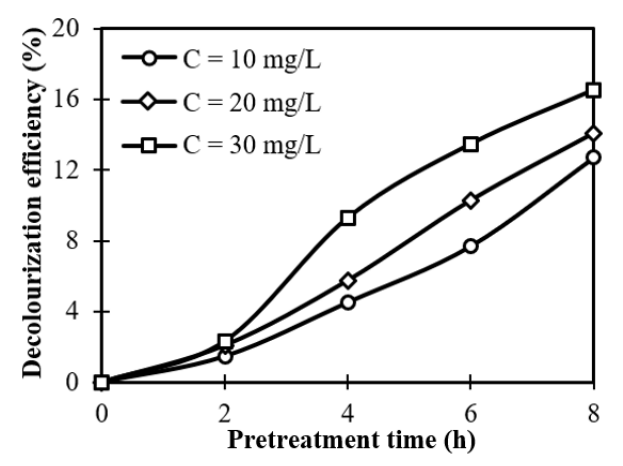

Fig. 3. Effect of ozone concentration on decolourization efficiency of UV irradiation/ozonation pretreatment.

The enhancement effect of higher $\mathrm{O}_{3}$ concentration on decolourization is more perceptible if the pretreatment duration exceeds $2 \mathrm{~h}$. When the pretreatment time equals to $2 \mathrm{~h}$, the variation in decolourization efficiency with different $\mathrm{O}_{3}$ concentration is trivial. Herein, the $\mathrm{UV} / \mathrm{O}_{3}$ mediated reactions occur very slowly, plausibly imputed to low power and photon energy of UV irradiation. In this study, a general-purpose mercury-vapor UV lamp is used for UV irradiation due to the carcinogenic concern of UV. For lighting purpose, the UV lamps are usually fabricated to generate UV-A light $(\lambda=315-400 \mathrm{~nm})$ that visible to naked eye. In contrast, UV germicidal lamps mainly emit UV-C light $(\lambda=100-280 \mathrm{~nm})$. According to the formula of photon energy in Eq. (16), UV-A light with greater $\lambda$ is weaker than UV-C light [12]. Indeed, the decolourization could be possibly improved by employing UV source with higher power and shorter wavelength. The parametric influence of UV irradiation is not addressed in the current work but will be investigated in future work.

$$
\mathrm{E}=\mathrm{hc} / \lambda
$$

where $\mathrm{E}$ is the photon energy $(\mathrm{J}), \mathrm{h}$ is the Planck constant $\left(6.63 \times 10^{-34} \mathrm{~J} \cdot \mathrm{s}\right), \mathrm{c}$ is the speed of light in vacuum $(3 \mathrm{x}$ $10^{8} \mathrm{~m} / \mathrm{s}$ ), and $\lambda$ is the wavelength (nm).

\subsubsection{Effect of ozone flow rate}

In this part, initial $\mathrm{pH}$ of 12 and ozone concentration of 30 $\mathrm{mg} / \mathrm{L}$ were employed to discover the effect of ozone flow rate. Based on Fig. 4, decolourization efficiency of UV irradiation/ozonation with different $\mathrm{O}_{3}$ flow rate could be ranked as $3 \mathrm{~L} / \min (16.52 \%)>2 \mathrm{~L} / \min (14.36 \%)>1$ $\mathrm{L} / \mathrm{min}(5.44 \%)$. As $\mathrm{O}_{3}$ flow rate raised from $1-3 \mathrm{~L} / \mathrm{min}$,

\footnotetext{
* Corresponding author: lam.mankee@utp.edu.my
} 
dark brown compost solution progressively faded. Both $\mathrm{O}_{3}$ concentration and flow rate enhance decolourization of compost solution if their magnitude increased. Withal, the influence of $\mathrm{O}_{3}$ flow rate on decolourization is much more significant than $\mathrm{O}_{3}$ concentration because of better mixing at high $\mathrm{O}_{3}$ flow rate. Ozonation aerates compost solution by bubbling $\mathrm{O}_{3}$ to be homogenous, thereby contributes to uniform degradation throughout the solution. High $\mathrm{O}_{3}$ flow rate increases the bubbling rate of $\mathrm{O}_{3}$ to the compost solution, which in turns more $\mathrm{HO}^{*}$ formation to degrade chromophoric humus particles. Likewise, the dependence of decolourization efficiency on $\mathrm{O}_{3}$ flow rate is low if the pretreatment is performed less than $2 \mathrm{~h}$. In short, optimal parameters for UV irradiation/ozonation are initial $\mathrm{pH}$ of $12, \mathrm{O}_{3}$ concentration of $30 \mathrm{mg} / \mathrm{L}$, and $\mathrm{O}_{3}$ flow rate of $3 \mathrm{~L} / \mathrm{min}$. For the microalgae cultivation, compost solution was decolourized by UV irradiation/ozonation for $24 \mathrm{~h}$ at optimal parameters. As pretreatment prolonged from 8 $24 \mathrm{~h}$, decolourization efficiency greatly improved from $16.52-40.88 \%$.

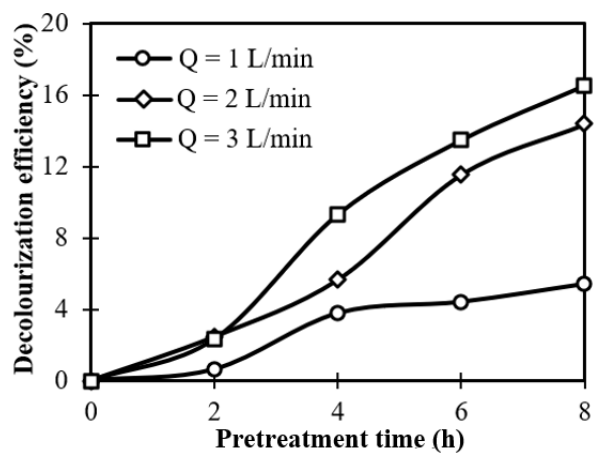

Fig. 4. Effect of ozone flow rate on decolourization efficiency of UV irradiation/ozonation pretreatment.

\subsection{Microalgae cultivation}

\subsubsection{Effect of UV irradiation/ozonation pretreatment}

C. vulgaris was autotrophically cultivated with 10 vol.\% compost solutions (untreated and treated) to elucidate the effect of UV irradiation/ozonation. Microalgae growth is measured in terms of its dry weight. Fig. 5 compares the growth performance of microalgae cultivated with treated and untreated compost solution. Both cultivations show a typical growth curve consisting of three common phases, viz. lag phase (slow growth), log phase (rapid growth), and stationary phase (static growth). With treated compost solution, the lag phase, log phase, and stationary phase occurred on day 1-2, 2-12, and 12-14, singly. Utilization of untreated compost solution shifted lag phase, log phase, and stationary phase to day $1-8,8-13$, and 13-14, singly. UV irradiation/ozonation increases the length of log phase by remarkably shortens lag phase. Decolourized compost solution allows a greater light transmission than untreated one, so $C$. vulgaris grew faster in treated compost solution because of its higher light uptake rate. At day 14, $0.88 \mathrm{~g} / \mathrm{L}$ and $0.58 \mathrm{~g} / \mathrm{L}$ of dried microalgae were obtained from the cultivation with treated and untreated compost solution, respectively. After the pretreatment of compost solution, specific growth rate $(\mu)$ improved from $0.14-0.19 \mathrm{~d}^{-1}$ while biomass productivity (B) raised from $0.040-0.065$ $\mathrm{g} /(\mathrm{L} \cdot \mathrm{d})$.
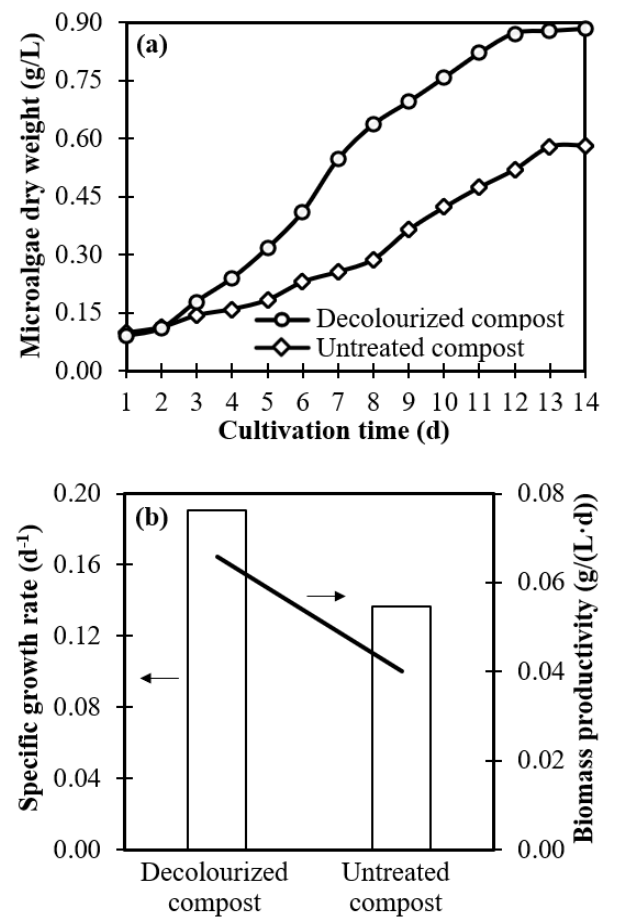

Fig. 5. Growth performance of microalgae using compost solution (treated and untreated): (a) microalgae dry weight and (b) specific growth rate and biomass productivity.

\subsubsection{Effect of decolourized compost solution concentration}

Autotrophic cultivation of $C$. vulgaris was performed by adding different concentration of decolourized compost solution ( $2-10$ vol.\%). Based on Fig. 6, the increase in concentration of decolourized compost solution enhances microalgae dry weight $(\mathrm{N})$, specific growth rate $(\mu)$, and biomass productivity (B). Previous study discovered the compost solution has essential nutrients $(\mathrm{N}, \mathrm{P}, \mathrm{K}, \mathrm{Ca}, \&$ $\mathrm{Mg}$ ) for microalgae growth [10]. Significant improvement of $\mathrm{N}, \mu$, and $\mathrm{B}$ was noticed as the decolourized compost solution concentration raised from $2-6$ vol.\%. Beyond $6 \mathrm{vol} . \%$, any further increment of decolourized compost solution concentration did not help much in $C$. vulgaris growth, as indicated by slight increase of $N, \mu$, and $B$. At day 14 , microalgae cultivation accomplished the highest $\mathrm{N}(0.88 \mathrm{~g} / \mathrm{L}), \mu\left(0.19 \mathrm{~d}^{-1}\right)$ and $\mathrm{B}(0.065 \mathrm{~g} /(\mathrm{L} \cdot \mathrm{d}))$ with the addition of 10 vol.\% decolourized compost solution.

\footnotetext{
* Corresponding author: lam.mankee@utp.edu.my
} 

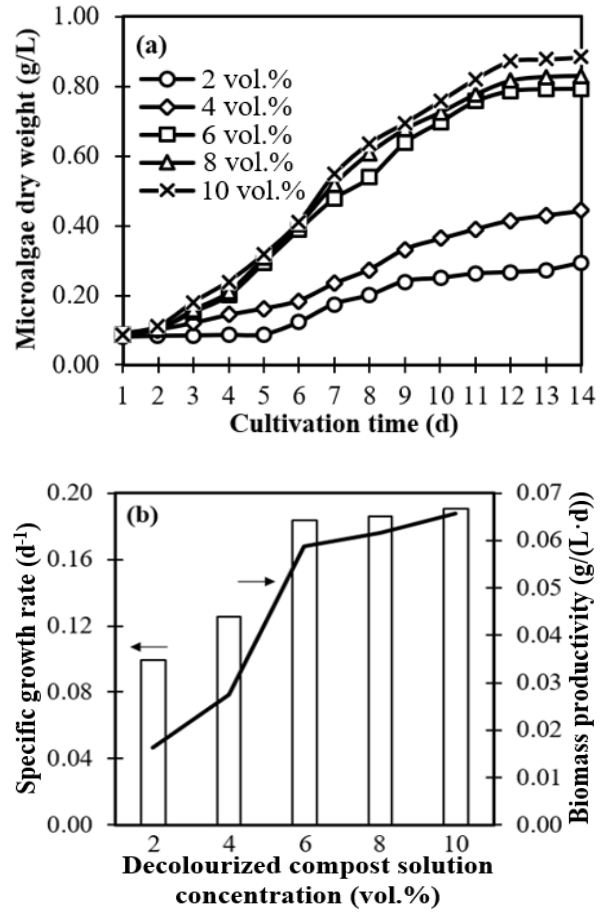

Fig. 6. Growth performance of microalgae using different concentration of treated compost solution: (a) microalgae dry weight and (b) specific growth rate and biomass productivity.

\subsection{Lipid content of microalgae}

Dried microalgae from cultivation with untreated and treated compost solution were analyzed for lipid content. For a fair comparison, only microalgae cultivated with 10 vol.\% compost solution were selected. After compost solution decolourized with UV irradiation/ozonation, the microalgal lipid content of C. vulgaris increased from 15 - 20 wt.\%. It is not surprised that $C$. vulgaris cultivated with treated compost solution have greater lipid content. Since microalgal lipids are primary metabolites, a greater lipid productivity could be predicted from higher biomass productivity of autotrophic cultivation.

\section{Conclusion}

UV irradiation, ozonation, UV irradiation/ozonation were tested to decolourize compost-derived liquid fertilizer for enhanced microalgae growth during cultivation. Highest decolourization efficiency (16.52\%) was achieved by the UV irradiation/ozonation after $8 \mathrm{~h}$ without compromising the preservation of nutrient (nitrate ions). It is surmised that UV irradiation and ozonation synergistically degrade the chromophoric humus particles in compost solution via $\mathrm{UV} / \mathrm{O}_{3}$-mediated reactions. Optimal parameters of the UV irradiation/ozonation pretreatment were initial $\mathrm{pH}$ of 12 , $\mathrm{O}_{3}$ concentration of $30 \mathrm{mg} / \mathrm{L}$, and $\mathrm{O}_{3}$ flow rate of $3 \mathrm{~L} / \mathrm{min}$. Alkaline $\mathrm{pH}$ favours the formation of highly reactive $\mathrm{HO}^{*}$ via the interaction between $\mathrm{O}_{3}$ and $\mathrm{HO}^{-}$, thereby facilitates better decolourization. Higher $\mathrm{O}_{3}$ concentration and flow rate introduce more $\mathrm{O}_{3}$ species for oxidative degradation; additionally, greater flow rate also improves homogeneity of reaction throughout the solution. Compost solution was then pretreated by UV irradiation/ozonation using optimal parameters for Chlorella vulgaris microalgae cultivation. C. vulgaris grew better in medium that supplemented with decolourized compost solution rather than untreated one. The improvement of microalgae growth is mainly due to higher light transmission of cultivation medium. Optimal concentration of treated compost solution in medium was 6 vol.\%. Howbeit, 10 vol.\% treated compost solution gave highest biomass productivity. For autotrophic cultivation of $C$. vulgaris that added with $10 \mathrm{vol} . \%$ compost solution, UV irradiation/ozonation increased its lipid content from $15-20$ wt. $\%$.

\section{Acknowledgement}

The authors would like to acknowledge the financial support from Universiti Teknologi PETRONAS (YUTP-FRG with cost centre 0153AA-H46). Besides, financial support from Ministry of Higher Education Malaysia through Higher Institution Centres of Excellence (HICoE) award to Centre for Biofuel and Biochemical Research (CBBR) is duly acknowledged (cost centre (015LC0-192).

\section{References}

1. H.M. Amaro, A.C. Guedes, F.X. Malcata. Appl. Energ. 88, 3402-10 (2011)

2. L. Brennan, P. Owende. Renew. Sustain. Energ. Rev. 14, 557-77 (2010)

3. M.K. Lam, K.T. Lee. Appl. Energ. 94, 303-8 (2012)

4. N.M. Dang, K. Lee. J. Ind. Eng. Chem. 59, 297-303 (2018)

5. L. Wang, M. Min, Y. Li, P. Chen, Y. Chen, Y. Liu, et al. Appl. Biochem. Biotechnol. 162, 1174-86 (2010)

6. S. Chinnasamy, A. Bhatnagar, R.W. Hunt, K.C. Das. Bioresour. Technol. 101, 3097-105 (2010)

7. M-K. Ji, H-C. Kim, V.R. Sapireddy, H-S. Yun, R. AbouShanab, J. Choi, et al. Appl. Microbiol. Biotechnol. 97, 2701-10 (2013)

8. M.H. Wong. Agr. Wastes. 12, 225-33 (1985)

9. L.D. Zhu, Z.H. Li, D.B. Guo, F. Huang, Y. Nugroho, K. Xia. Bioresour. Technol. 223, 296-300 (2017)

10. X.B. Tan, M.K. Lam, Y. Uemura, J.W. Lim, et al. Energ. Convers. Manage. 164, 363-73 (2018)

11. B. Riaño, M. Coca, M.C. García-González. Chemosphere. 117, 193-9 (2014)

12. Y.W. Cheng, Y.S. Chang, K.H. Ng, T.Y. Wu, C.K. Cheng. J. Clean. Prod. 162, 205-19 (2017)

13. R.C.B. Chidambara, H.Q. Li. Chem. Eng. Sci. 60, 530511 (2015)

14. H. Selcuk. Dyes Pigments. 64, 217-22 (2005)

15. S. Yen, S. Sokolenko, B. Manocha, A. Patras, et al. Biotechnol. progr. 30, 1190-5 (2014)

16. K.H. Ng, Y.W. Cheng, M.R. Khan, C.K. Cheng. J. Environ. Manage. 184, 487-93 (2016)

17. B. Kasprzyk-Hordern, M. Ziółek, J. Nawrocki. Appl. Catal. B: Environ. 46, 639-69 (2003)

18. F.J. Beltran. Ozone Reaction Kinetics for Water and Wastewater Systems. (2003)

19. J. Leusink. Oxidation Potential of Ozone. (2016)

20. W. Koppenol. FEBS Let. 140, 169-72 (1982)

21. Armstrong D, Huie R, Lymar S, Koppenol W, et al. BioInorganic Reaction Mechanisms. 9 (2013)

22. P. M. Wood. FEBS Let. 44, 22-4 (1974)

\footnotetext{
* Corresponding author: lam.mankee@utp.edu.my
} 
23. Y. Deng, R. Zhao. Curr. Pollut. Rep. 1, 167-76 (2015)

* Corresponding author: lam.mankee@utp.edu.my 